\title{
Models for Managing Production Systems of Machine-Building Enterprises Based on the Development and Using of Their Digital Twins
}

\author{
Vitalii A. Dolgov ${ }^{1}$, Petr. A. Nikishechkin ${ }^{1,2, *}$, Vladimir E. Arkhangelskii ${ }^{3}$, Pavel I. Umnov ${ }^{4}$ and Alexey A. Podkidyshev ${ }^{1}$ \\ ${ }^{1}$ LLC "Digital Systems Factory", Moscow, Russia \\ ${ }^{2}$ Moscow State Technological University "STANKIN", RU-127055, Moscow, Russia \\ ${ }^{3}$ LLC "AAMC", RU-121471, Moscow, Russia \\ ${ }^{4}$ PJSC «DSPP», RU-141700, Moscow region, Dolgoprudny, Russia
}

\begin{abstract}
The paper discusses the goals and objectives of creating digital twins of the production system of a machine-building enterprise. The data structure of the information model of the production system of a machine-building enterprise, which is the basis for building a digital twin, is presented. The paper shows the main approaches to managing a production system based on the construction of its digital twin. It is revealed that along with traditional approaches to PS management by forming recommendations in terms of PS engineering and its operation, the choice of the most rational PS management algorithms that take into account the peculiarities of the production process organization and ensure the formation of production schedules that take into account PS reliability indicators has a great potential. It is proposed to use a specialized language of DPML to describe the information model of the PS through the "product-processresource" paradigm, which ensures the coordination of the processes of forming recommendations in terms of engineering and operation of the PS, as well as the choice of the most rational algorithm for managing the PS.
\end{abstract}

\section{Introduction}

Modern trends in the development of information technologies in the world in recent years are inextricably linked with the emergence of new approaches to the design and organization of production. An important transition period was the emergence of the concept of "Industry 4.0", the main idea of which is to digitalize production, increase the level of automation and change the role of man in production. In the digital economy, new technologies associated with high - tech industry are emerging - digital twins and digital shadows. These concepts have many interpretations and definitions today, but in a generalized form, a digital twin is a virtual copy of an object/process/system with a given level of compliance (adequacy). The main task of building any digital twin is to diagnose and predict the operation of the object/process/system. a digital twin of an object / process / system can be created and used at various stages of the object/process/system life cycle to solve specific tasks. The concept of digital twins is relevant in many industries, such as energy, transport, and construction, but it primarily works in the high-tech industry [1-3].

The creation of digital twin of objects/products is in some way solved with the use of product support and life cycle management technologies: CALS (Continuous Acquisition and Life Cycle Support) and PLM (Product
Lifecycle Management) - organizational and technical systems that support all information about the product and related processes from design and production to decommissioning [4].

Speaking about the creation of a digital twin of a complex system, for example, a machine-building enterprise, it can be noted that today there are no real examples, as well as tools that allow creating a digital model of an entire enterprise with a high level of adequacy, taking into account all production processes (technological, resource management, accounting, labor protection, safety, etc.), their regulatory and resource support [5].

Thus, it is advisable to talk about the gradual construction of a digital twin of the enterprise, in accordance with clear aims and objectives that need to be reached through its functioning. This paper discusses the issues and aspects of building a digital twin of a production system (PS) of an enterprise, includes work equipment, products, production processes (technological processes, maintenance and repair processes, transportation and storage processes) and production planning systems and modeling and analysis tools, the joint functioning of which makes it possible to produce products [2,6-9].

\footnotetext{
Corresponding author: npa@digitalfabrika.ru
} 


\section{Theoretical aspects of building a digital twin of the production system of a machine-building enterprise}

Building a digital twin of the PS can be divided into two stages: digital twin of PS prototype and digital twin of PS instance (Fig. 1).

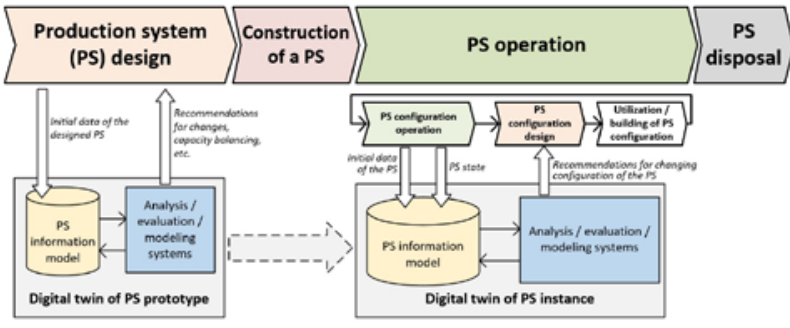

Fig. 1. Building a digital twin of a production system at various stages of its life cycle

At the design stage of the production system, a digital twin of the PS prototype is developed, on the basis of which technological solutions are tested and recommendations for changing design solutions are formed [7-11]. It is possible to distinguish the main characteristics of digital twin of the PS prototype of a machine-building enterprise:

- developed before the production system is available based on design decisions;

- does not include measurement data and reports coming from a real system;

- based on a highly accurate mathematical model;

- allows us to evaluate the behavior of a real system based on its model;

- used to further create the digital twin instance of the PS [5].

At the operational stage, a digital twin of the PS instance is being developed. At this stage, the PS is subject to periodic configuration changes due to changes in the product range and production program. The digital twin of PS instance of the machine-building enterprise is developed on the basis of the digital twin of the PS prototype and has additional characteristics:

- corresponds to a specific PS;

- allows us to diagnose and evaluate the behaviour of the PS based on its model, including statistical data on its work;

- contains information about the model settings, control parameters, sensor data and statistics about the operation of the PS.

As figure 1 shows, both the digital twin of the PS prototype and the digital twin of the PS instance are based on its information model, as well as on analysis, evaluation and modelling systems [10].

Build a digital twin PS of machine - building enterprises are almost impossible without functioning information systems of the enterprise, which is the source of data for constructing the information model of the substation and performing coordinated control of production and business processes at various levels of enterprise management [11].
The information model of the production system should contain machine-oriented data for their subsequent processing in analysis and modeling systems. the data set contained in the information model should be refined for specific purposes and tasks of the production system analysis. Figure 2 shows the data flows for the formation of the information model of the PS and further analysis and modeling in the corresponding systems.

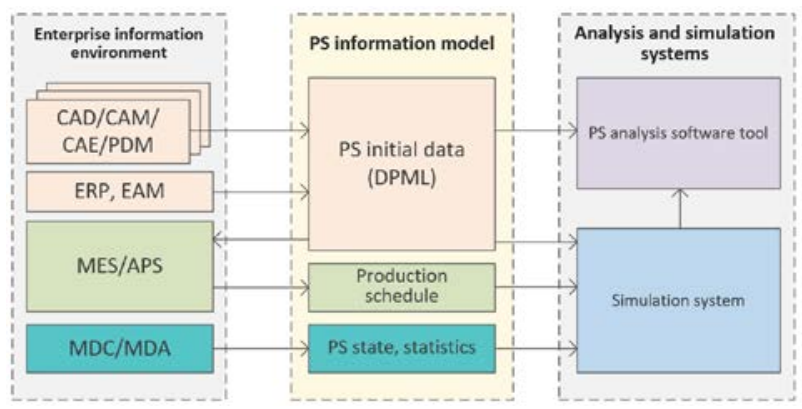

Fig. 2. Architecture for building a digital twin of a PS instance

The information model of the PS can be divided into three blocks: the initial data of the PS, the production schedule formed in accordance with the production plan, as well as a set of data on the current state of the PS and statistics of its work. To describe the initial data on the $\mathrm{PS}$, it is proposed to use the universal language for describing products, processes and resources DPML (Discrete Process Modeling Language), which allows describing the PS in the form of a block diagram in a visual graphical notation. table 1 provides a description of each of the data blocks, the main sources of information, the format of presentation and the degree of variability of data within a single PS cycle.

Table 1. Structure of building an information model of the PS for the development of a digital twin

\begin{tabular}{|c|c|c|c|}
\hline Data & References & $\begin{array}{c}\text { Data } \\
\text { descriptio } \\
\text { n format }\end{array}$ & $\begin{array}{c}\text { Estimate of } \\
\text { variability } \\
\text { of the data } \\
\text { during } \\
\text { operation }\end{array}$ \\
\hline $\begin{array}{l}\text { Nomenclature } \\
\text { of } \\
\text { manufactured } \\
\text { products } \\
\text { (products) }\end{array}$ & \multirow{2}{*}{$\begin{array}{l}\text { Production } \\
\text { preparation and } \\
\text { product lifecycle } \\
\text { management } \\
\text { systems (PDM, } \\
\text { CAD/CAE, } \\
\text { CAM/CAPP) }\end{array}$} & \multirow{3}{*}{$\begin{array}{l}\text { Universal } \\
\text { description } \\
\text { language } \\
\text { DPML } \\
\text { (Discrete } \\
\text { Process } \\
\text { Modeling } \\
\text { Language) }\end{array}$} & $\begin{array}{l}\text { Conditionally } \\
\text { constant data }\end{array}$ \\
\hline $\begin{array}{l}\text { Production } \\
\text { processes }\end{array}$ & & & $\begin{array}{l}\text { Conditionally } \\
\text { constant data }\end{array}$ \\
\hline $\begin{array}{l}\text { Production } \\
\text { resources }\end{array}$ & $\begin{array}{l}\text { Enterprise } \\
\text { resource and } \\
\text { production } \\
\text { management } \\
\text { systems (ERP) }\end{array}$ & & $\begin{array}{l}\text { Conditionally } \\
\text { constant data }\end{array}$ \\
\hline $\begin{array}{l}\text { Production } \\
\text { schedule }\end{array}$ & $\begin{array}{l}\text { Production } \\
\text { process } \\
\text { management and } \\
\text { planning systems } \\
\text { (MES, APS) }\end{array}$ & $\begin{array}{l}\text { Specialized } \\
\text { schedule } \\
\text { file }\end{array}$ & $\begin{array}{l}\text { Periodically } \\
\text { changing data }\end{array}$ \\
\hline $\begin{array}{l}\text { PS status, } \\
\text { statistics }\end{array}$ & $\begin{array}{l}\text { Monitoring and } \\
\text { dispatching } \\
\text { systems (MDC, } \\
\text { MDA) }\end{array}$ & Database & $\begin{array}{l}\text { Changing } \\
\text { data }\end{array}$ \\
\hline
\end{tabular}


The main block of the information model is the initial data on the PS described in the "product-processresource" paradigm, which can be attributed to conditionally unchanged data within a single cycle of PS operation. This block contains information about the range of manufactured products, production processes and production resources of the PS in the form of a DPML model. This model is a data source for the formation of local information models for various consumer information systems, which can include MES/APS systems, as well as PS analysis and modelling systems [10,12].

System MDC/MDA class required to collect information about the machines and monitoring jobs, which allows to collect statistical data on the PS and determine its reliability taken into account in the further analysis of the PS and the simulation of its operation. MDC/MDA systems automatically record the time and duration of operation/downtime/emergency conditions of the machine, as well as allow to collect data on technological modes (feed, speed, load), currently running control program (CP), error codes, causes of downtime, etc [13].

The production schedule formed in systems of the MES/APS class can be considered the main tool for managing the PS, provided that the basic data block - the source data of the PS presented in the form of a DPML model-is relatively unchanged. PS can have different levels of stability in individual areas, and for their accounting, it is necessary to conduct a preliminary analysis of PS, as well as verification of the generated production schedules. To solve these problems, a comprehensive solution is proposed, including analytical (computational) methods, as well as simulation modelling [14-17].

Analysis of the enterprise's PS and decision-making support for its management can be carried out using a specialized software tool, the main functions of which are:

- pre-processing and verification of data required for PS analysis;

- calculation of a set of production and economic indicators of the efficiency of the PS functioning on the basis of initial data (product range, technological processes, production resources, production plan). The tool provides the ability to calculate indicators for different levels of enterprise decomposition (enterprise, shop, site, workplace);

- analysis of simulation results, including calculation of performance indicators of the enterprise's PS;

- generating analytical reports based on the results of calculating performance indicators and modeling results necessary to support decision-making by managers at various levels [5,18].

The software tool for conducting production system analysis allows us to perform a basic calculation of PS performance indicators both on the basis of initial data about the system and on the basis of simulation results, as well as to analyze and compare them with actual indicators obtained from MDC/MDA systems. The production system at this stage is considered as a stable system. The result of the software tool is the formation of analytical reports containing the necessary data in a visually understandable form, providing decisionmaking support for managers at various levels [8,9,1922].

The next stage of the analysis is the simulation of the functioning of the entire PS or its individual divisions. simulation modeling in the form of an algorithm reproduces the logic of the PS functioning in time and allows us to take into account the sequence and interaction of production processes, as well as random events. In simulation modeling, the PS is considered as an unstable system and random factors arising in the PS are taken into account. System simulation discrete industries PlantTwin allows to consider, besides the basic information about the production system, the following number of additional factors that affect the functioning of the PS: irregular execution time of technological operations; delays and deviations of the timing of delivery of components; different time transportation of workpieces between production units; limitation of the buffer capacity (warehouses, storage) in various stages of the production cycle; unscheduled repairs of process equipment with regard to crashes; repairs of equipment by operating time, etc. [23-26]. Accounting for the above factors in other operational scheduling systems is usually not carried out, but in the course of production, these factors can have a significant impact on the implementation of the production plan.

Thus, at this stage of the analysis of the production system with the use of simulation modeling, it is possible to solve the following tasks:

- quantitative assessment of the production capacity of the considered production system for the implementation of the production program;

- justification of the necessary composition and quantity of technological equipment (jobs) to run a given production program;

- validation of production plans and schedules using simulation;

- analysis of the behavior of the production system and development of organizational and technological recommendations to improve its efficiency.

Also, systems of this class allow to model different experiments and simulate the system behavior under different scenarios: for example, to assess the impact of organizational and technological solutions in the work of the PS, which allows for detailed and rapid analysis of design decisions [12,27].

The results of the analysis of PS based on building its digital twin, one way to control is to change the logic and algorithms for building a production schedule that does not require modification of the unit source data PS. Since simulation systems take into account a number of additional factors that affect the functioning of the PS, based on the simulation results, it is possible to give a more adequate answer about the feasibility of the production schedule and the stability of the PS with the selected control logic. thus, for effective PS management, it is necessary to perform preliminary verification of production schedules generated using various algorithms and determine the best of them [2830]. 
Another way to manage the PS is to form recommendations regarding the engineering of the PS or the operation of the PS, i.e. changing the initial data of the PS. Best practices for engineering PS can be attributed to change of the scheme of cooperation, the composition of jobs and equipment, structures, technological processes, technological equipment and technological conditions, the degree of automation of the technological process (reduction of the human factor), technological procedure of manufacturing products, increasing the effectiveness of the system of technological preparation of production and flexibility of PS (reduction of changeover time). Suggestions for changing the structure of workshops, organization of the maintenance and repair system, processes and algorithms of the logistics system, conditions for the development of production schedules, work schedules of workshops and sites, personnel composition can be considered as recommendations for the operation of PS [31-34].

\section{Conclusions}

Thus, the solution of the problem of effective PS management using its digital twin is based on the task of creating an adequate and consistent information model that defines the requirements for the data structure necessary to solve the corresponding problems, as well as for the composition and interaction of information systems containing and processing this data. The problems of analysis, modelling, valuation, forecasting and management of the PS is impossible without a coherent, logically related source data of it, as18 well as the complex interactions of systems of operativecalendar planning and systems analysis, evaluation and modelling of the PS.

It is shown that along with traditional approaches to PS management by forming recommendations in terms of PS engineering and its operation, the choice of the most rational PS management algorithms that take into account the peculiarities of the organization of the production process has a great potential. The selected algorithms ensure the formation of production schedules that take into account the reliability indicators of the PS. The production schedules formed in this way provide a higher stability of the PS during their execution, which is confirmed by the results of analysis and modelling using both computational methods and simulation modelling $[20,21,26]$.

The article suggests the use of a specialized DPML language to describe the information model of the PS through the "product-process-resource" paradigm, which ensures the coordination of the processes of forming recommendations in terms of engineering and operation of the PS, as well as the choice of the most rational algorithm for managing the PS.

\section{Acknowledgments}

Funding: This research was funded by Ministry of Science and Higher Education of the Russian Federation, Grant No. 0707-2020-0025.

\section{References}

1. S.N. Grigoriev, V.A. Dolgov, A.A. Leonov, IOP Conference Series: Materials Science and Engineering, 971 (2020)

2. A.I. Borovkov, Yu.A. Ryabov, Proceedings of the scientific and practical conference with foreign participation "Digital transformation of the economy and industry", 234-245 (2019)

3. A.V. Gusarov, S.N. Grigoriev, M.A. Volosova, Y.A. Melnik, A. Laskin, D.V. Kotoban, A.A. Okunkova, J. Mater. Process. Technol., 261, 213 (2018)

4. V.E. Arkhangelskii, Requirements for production planning systems in the context of the concept "Industry 4.0 "[Electronic resource], VII international forum "Information technologies in the service of the military-industrial complex of Russia". Yalta, (2018, April 24-26), URL: http://итопк.RF/wpcontent/uploads/2018/05/Arhangelskij.pdf (2018)

5. R.A. Nezhmetdinov, P.A. Nikishechkin, A.N. Nikich, International Russian Automation Conference (RusAutoCon), Sochi: IEEE, 1-4 (2018)

6. C.L. Tomovic, L.B. Ncube, A. Walton, M. Grieves, International Journal of Manufacturing Technology Management, 19, 167-179 (2010)

7. A. Prokhorov, A.I. Borovkov, Digital twin. Analysis, trends, world experience (AliancePrint, Moscow, 2020)

8. Y. Cai, B. Starly, P. Cohen, Y. Lee, Procedia Manufacturing, 10, 1031-1042 2017.

9. J. Cheng, H. Zhanga, F. Tao, C. Juang, Robotics and Computer Integrated Manufacturing, 62 (2020).

10. V.E. Arkhangelskii, Operational model of production as a standard component of means of operational planning of order-based production [Electronic resource], VI international forum "Information technologies in the service of the military-industrial complex of Russia", Izhevsk, (2017, June 20-22). URL:http://aamc.ru/wpcontent/uploads/2018/06/ITOPK2017-

ArkhangelskyVE-WithNotes_v102.pdf (2017)

11. P.A. Nikishechkin, N.Yu. Chervonnova., A.N. Nikich, Lecture Notes in Electrical Engineering 18761100, 641, 181-188 (2020)

12. G.M. Martinov, R.L. Pushkov, L.I. Martinova, N.V. Kozak, S.V. Evstafieva, MATEC Web of Conferences, 329, 03026 (2020).

13. S.N. Grigoriev, V.A. Dolgov, P.I. Umnov, N.N. Fokin, O.S. Proshkina, MATEC Web of Conferences, 329, 03076 (2020)

14. J. Davis, T. Edgar, J. Porter, J. Bernaden, M. Sarli, Computers and Chemical Engineering, 47, 145-156 (2012)

15. Y. Lu, C. Liu, K. Wang, H. Huang, X. Xu, Robotics and Computer Integrated Manufacturing, 61 (2020). 
16. S.N. Grigoriev, V.A. Dolgov, P.A. Nikishechkin, N.V. Dolgov, IOP Conference Series: Materials Science and Engineering, 971 (2020)

17. V.A. Dolgov, A.A. Kabanov, Automation. Modern technologies, 72(4), 178-184 (2018)

18. P.A. Nikishechkin, S.S. Ivashin, V.E. Chernenko, A.A. Malykhanov, N.V. Dolgov, MATEC Web of Conferences, 329, 03075 (2020)

19. V.A. Dolgov, A.A. Podkidyshev, I.V. Datsyuk, A.A. Kabanov, M.A. Vasiltsov, Automation. Modern technologies, 72(8), 350-354 (2018)

20. M.A. Volosova, S.N. Grigoriev, E.A. Ostrikov, Mech. Ind., 17, 720 (2016)

21. S.N. Grigoriev, D.A. Masterenko, V.I. Teleshevskii, P.N. Emelyanov, Meas. Tech, 55(11), 1311 (2013)

22. R.S. Khmyrov, S.N. Grigoriev, A.A. Okunkova, A.V. Gusarov, Procedia 56, 345 (2014)

23. P.A. Nikishechkin, N.Y. Chervonnova, A.N. Nikich, IOP Conference Series: Materials Science and Engineering, 709(4), 044065 (2020)

24. S.N. Grigoriev, G.M. Martinov, Procedia CIRP, 46, 525 (2016)

25. G.M. Martinov, P.A. Nikishechkin, A.Al. Khoury, A. Issa, IOP Conf. Ser.: Mater. Sci. Eng, 919(3), 032030 (2020)

26. G.M. Martinov, R.L. Pushkov, L.I. Martinova, N.V. Kozak, S.V. Evstafieva, MATEC Web of Conferences, 329, 03026 (2020).

27. S.N. Grigoriev, G.M. Martinov, Procedia CIRP, 1(1), 238 (2012)

28. V.A. Grechishnikov, S.N. Grigoriev, P.M. Pivkin, et. al., EPJ Web Conf., 224, 05001 (2019)

29. A.S. Metel, V.P. Bolbukov, M.A. Volosova, S.N. Grigoriev, Yu.A. Melnik, Instrum. Exp. Tech., 57(3), 345 (2014)

30. V.A. Grechishnikov, Y.E. Petukhov, P.M. Pivkin, Meas Tech, 58, 848-853 (2015)

31. A.P. Okunev, A.I. Borovkov, A.S. Karev, D.O. Lebedev, V.I. Kubyshkin, S.P. Nikulina, A.A. Kiselev, Russian Engineering Research, 39(6), 453-458 (2019)

32. S.N. Grigoriev, P.M. Pivkin, V.A. Grechishnikov, Y.E. Petukhov, M A. Volosova, A.B. Nadykto, 11540, 03076 (2020)

33. S.N. Grigoriev, M.A. Volosova, A.A. Okunkova, S.V. Fedorov, K. Hamdy, P.A. Podrabinnik, A.N. Porvatov, J. Manuf. Mater. Process., 4(3), 96 (2020)

34. S.N. Grigoriev, V.A. Grechishnikov, M.A. Volosova, X. Jiang, P.M. Pivkin, IOP Conference Series: Materials Science and Engineering, 971, 022065 (2020) 